\title{
English-Chinese Translation Strategies on Press Conference
}

\author{
Xuedong Shi \\ Foreign Language Department, Beijing Information Science \& Technology University, Beijing, China
}

\begin{abstract}
This paper studies the application of domesticating and foreignizing approaches in the translation of Premier Wen Jiaobao's press conferences held in recent years. It gives a general introduction of the development of domestication and foreignization and compares the merits and flaws of them in theoretical level in the first place. Then, a few specific examples abstracted from the press conferences are given to further illustrate how both the approaches are used in the practice. In addition, this research puts forward some critics on some of the applications of domesticating method and foreignizing method in the translation of the press conferences, and provides improved versions to better those examples that are pointed out. According to the analysis of the development of the domestication and foreignization theory and the examples extracted from the press conferences, the author discovers that domestication is the main method adopted in the translation of current press conferences. However, with the rapid globalization, every nation is paying increasing attention to its national culture. So foreignization is a general trend.
\end{abstract}

Index Terms - domestication, foreignization, interpretation, press conferences

\section{Theoretical Review on Domestication AND ForeigniZATION IN TRANSLATION Home AND ABROAD}

Recent years have witnessed the great attention aroused by Premier Wen Jiaobao's Press Conference home and abroad. Premier Wen quoted and cited extensively, which impressed the public. In his speech, there were large amount of traditional Chinese poetry and idioms, as well as expressions involving every aspect of world economy, politics, culture and so on. Besides, the interpreters are among the top talents. Therefore, the translation of the press conference is worth studying. This paper, mainly from the perspective of domestication and foreignization, studies how the translator has delivered the content, as well as how to better the translation to some extent.

In his landmark work The Translator's Invisibility, Venuti, the American translation theorist firstly coined the terms of "domestication" and "foreignization". According to Venuti's theory, domestication is target-language culture oriented, and it can bring back the other culture as the familiar one. (Venuti, 2004). It requires the translator to take target-language readers' comprehension more into consideration. The translation should be adapted to the features of target language, in order to avoid readers' misunderstandings due to the differences of language and culture. But foreignization is source-language culture oriented and it accepts that cultural differences and wants to bring the readers the differences, keeping the original features of the source language. The translator should give priority to the source language, adopt the usual use of original words and phrases. In this way, the translation could reappear the exotic style and linguistic disparities of the source language. Friedrich Schleier, probably, was the first to expose the notion of domestication and foreignization in a most clarified way in an 1813 lecture. (Venuti, 2004).

The debate over which approach should be adopted under what conditions has lasted for hundreds of years, long before the emergence of the two terms. It was in the first place focused only on the linguistic level. Afterwards, in the 20th century, the debates attached more importance to cultural distances between the source text and the target text. The famous representative of domestication translation is Eugene Nida, who points out the communicative function of translation, suggesting that the choice of word should adjust so that it could custom different kinds of readers. Nida lays great emphasis on reader response. He determines that it is the most essential standards to judge the quality of translation. Nida believes it necessary to make changes and adjustments to the translated text under certain conditions. Besides Nida, many other translations theorists in the west also favor domesticating strategy. Among them, Susan Bassnet proposes the equivalence of cultural functions and approves of employing domesticating to handle linguistic and cultural differences in translation. Generally speaking, Nida's Formal and Functional Equivalences: formal equivalence focuses on providing some perception in the lexical, grammatical or structure of original text. Functional equivalence is based on the principle of equivalent effect. Studied diachronically, domestication has enjoyed great popularity among translators and translation critics in the translation history. Domestication has grown a deep root in China too. In China, the prestigious translators such as Lin Shu and Liangshiqiu are the devoted advocators of domestication theory and applied it to their translation works which enjoyed tremendous popularity among the readers.

Lawrence became a central figure in the translation field since his Translator's Invisibility went to press in 1986 in the U.S. As a deconstructionist, Venti presents a set of innovative points of view, say, cultural colonization and translator's invisibility in his revolutionary book. According to him, the aim of work is to force both the translators and readers to know the linguistic and cultural differences of the alien articles. (Venuti, 2004) In China, similar opinions 
emerged as early as the beginning of the 20th century though systematic study of translation lag behind the west. Translators such as Lin Shu and Liang Shiqiu were accused of having changed the original work brutally by many scholars, say, Lu Xun, who favored "rigid translation"-----putting forward the translation prince of faithfulness over smoothness. In modern China, the prestigious scholar Liu Yingkai points out the prevalence of domestication in The Wrong Track of Translation. Liu argues that domestication translation misrepresents the original text. Sun Zhili thinks the main task of translation is to deliver the thought and style of the original text. Xu Jianping suggests that foreignization should be used in English-Chinese translation as much as possible.

\section{Methodology: Translation of Premier Wen Jiaobao’s Press Conference}

During the practice of interpreting the press conference, domesticating translation is closer to the audience's listening habit. It removes the barrier of reading, listening and gaining the major information of the original work or what the speaker talks about for the audience. But it fails to realize the cultural communication and interactions, which lessens the beauty and the connotation of the source language and culture. However, at the press conference, where the main purpose is to exchange ideas, the primary task of interpretation is to pass on what the speaker is talking about. The interpreter shoulders less task of cultural exchange. Under such circumstances, we don't make excessive demands on interpreters to keep the original flavor of language expressions and speech style of the source language. Therefore, domesticating translation is usually adopted as a dominant strategy. Meanwhile, even when the source language is loaded with large amount of linguistic forms with cultural features, such as writings in classical Chinese, rhetoric phrases, and prevalent idioms, domesticating translation is still a priority alternative due to the requirement of shorttime results. Here, I give several examples to illustrate how domesticating translation is applied under different circumstances in the press conference.

On the spot of the press conference, it is a huge challenge for the interpreter to interpret when the speaker cites and quotes the classics, for great disparities exist between different cultural backgrounds and language forms.

Example1. Nida believes it necessary to make changes and adjustments to the translated text under certain conditions. The citation of the classics brings an obstacle of cultural differences to comprehension. So the interpreter has to remove the cultural divergences and bridge the cultural gaps by way of the interpretation. Since domestication is more often used when there is cultural conflict, the interpreter here adopts domesticating approach to avoid cultural conflicts. (Nida, 2004)

"gou li wo jia sheng si yi, qi yin huo fu bi qu zhi" is quoted from a poem written by the national hero Lin Zexu. The general idea of it is: As long as it is beneficial to our nation, it is worthy of sacrificing one's life. One could never escape or shrink from his responsibility because of his fear for the loss of wealth and honor.

"zhi wo zui wo, qi wei chun qiu" is from Confucius' words. It means: What I have done and said will be judged by the later generations, mixed with praise and blame. However, whatever others judge them, I will firmly persist in doing what I deem is right and of value.

The ancient Chinese language is extremely abstract. It often leaves out large amount of sentence constituents, leaving abundant room for readers to imagine. If the interpreter adopts foreignizing method in order to keep the pattern and flavor of the writings in classical Chinese, the audience who are non-Chinese speakers will no doubt be confused about the asyntatic translation. To the convenience of the comprehension of the foreign journalists on the spot, the interpreter dealt it with the domesticating approach, which accords with the expressing habit of English speakers.

Take the above sayings as an example: "gou li guo jia sheng si yi, qi yin huo fu bi qu zhi" is interpreted as "I shall dedicate myself to the interest of the country in life and death irrespective of personal weal and woe." The interpreter choose the view of first person to directly put Premier Wen into the saying, making others fully understand the premier's conviction.

"zhi wo zui wo" is translated as "There are people who will appreciate what I have done, but there will also be people who criticize me." Here, the interpreter translated the short phrase in a detailed explanation which is quite clear; "wei qi chun qiu" as "Ultimately, history will have the final say." "chun qiu" refers to history. The interpreter complete the meaning of the original phrase by adding the verbal phrase in the translation with "have the final say". With "ultimately", it emphasized the premier's tone in confidence and clear conscience.

Considering the burgeoning expressions, during the evolutional process of language, emerging phrases and expressions crop up here and there, and become part of the culture of Chinese characteristics after their prevalence. The domesticating approach adapts the translation to the language and cultural habit of the target-language audience.

Example2. It is clear to the source language readers what"jia dian xia xiang"and"qi che yi jiu huan xin"mean because the Chinese language is sometimes elliptical and abstract, with some ideas not fully expressed. But the foreigner would be puzzled if they are not explained clearly. Moreover, English is a logical language, which does not allow so much ellipsis in thinking as Chinese. Readers of English need a clear and complete expression. Therefore, the translator should spare no effort to draw out the meaning from the seemingly obscure Chinese language and give the complete meaning in the version. Only in this way can the translated version be called a successful one. Therefore, the domestication is adopted here in order to satisfy the culture of the target language. 
"jia dian xia xiang, qi che yi jiu huan xin" is interpreted as "subsidizing the sale of home appliances in the rural areas and the trade-in of second-hand automobiles with new ones ". By adding the verb "subsidize", foreign journalists would better understand the policy adopted by the government.

Example 3. Domestication is regarded as the best way to keep the fluency of the work for target readers. Advocators of this approach believe that by overcoming the linguistic and cultural barriers, a deeper comprehension of the work on the readers' part can be achieved. They hold the view that translators should not have a too high expectation on the readers or audience's intelligence and imagination or even impose the source-language culture mode upon them. Instead, they should try their utmost to recreate a world reflected by the source-language work as close as possible to the world and culture familiar to the readers and audience. Adjustments result in the smoothness in the translated work, ensued by effective communication and deep understanding is the outcome of this approach.

"lian zu fang" and "jing ji shi yong fang" are respectively translated as "low-rent apartments" and "affordable housing", which are very visual and clear in meaning by domesticating method. Some translator may translate "lan zu fang" and "jing ji shi yong fang" into "cheap housing" or "economical housing" according to the word "lian" and "jing ji", which evidently fails to explain how the housing is economical to common people.

Considering the Chinese common sayings, the press conference, both the Chinese journalists and the premier would sometimes express themselves by illustrating some common sayings which are close to people's life. At this moment, the interpreter would also choose the domesticating translation.

Example 4. "pai zhuan" is a popular net word, which means to criticize someone or something in one's own way. Sometimes it may develop into an attack. Apparently, "pai zhuan"is smartly interpreted into "critical" attitudes towards Premier Wen Jiaobao'sperformance. If the interpreter adopts foreignizing method, it would be difficult for foreign audience to catch the meaning. Since time is very limited for the interpreter to explain too much for the audience about the net word "pai zhuan", it is very clever to have it interpreted in the domesticating way.

Compared to domesticating method, foreignizing approach is less used in interpreting the press conference due to its flaws of being not that fluent and unacceptable for the audience. Though, it can better reappear the novel language style, social mentality and cultural environment of the foreign nations, which meets the requirement of some readers and audience for learning more about a different culture and language.

Since Premier Wen Jiaobao's press conference attracts more and more foreign journalists around the world in recent years, it is becoming increasingly necessary to pay more attention to spreading out and preserving Chinese culture through the conference. In this research, I have concluded two circumstances under which foreignizing approach is adopted.

With the rapid social and economic development since the foundation of the People's Republic of China, a large number of certain new political terms and expressions emerged as the times require. Even for those native English speakers, they would firstly check the cultural, social, economic and political background of those new words and phrases in order to comprehend and accept them into their language. Therefore, interpreters and translators conventionally adopt foreignizing method to deal with those words and phrases. For instance, "gai ge kai fang" is translated into "reform and opening up", "yi guo liang zhi " into "one country, two systems" and so on. There is no minor matter in diplomacy, any information error caused by interpretation would lead to the worst results. The interpreter must make sure the translation is safe and sound. It is inappropriate to deliberately cater to the foreign audience.

Example 5. Here "fa zhan de chu ji jie duan" is translated into "the primary stage of development", "quan mian shi xian xiao kang mu biao" into "build a moderately prosperous society in all respects", "zhong deng fad a guo jia" into "medium-developed country", "zheng zhen shi xian xian dai hua" into "achieve true modernization". They generally belong to literal translation, which means word-for-word translation. It is used to transform the meaning and structure of the original text directly into the form of target language. Literal translation is the most ordinary and effective way to retain the flavor of the original text and introduce the source-language culture in detail. Furthermore, it can introduce more expressions into target language and enrich the target-language culture.

Obviously, all these above-mentioned phrases and expressions are translated in a foreignizing way, without much explanation for the audience. This strategy is defined by Venuti as one that deliberately breaks target conventions by retaining something of the foreignness of the original (Shuttleworth\& Cowie, 2004). Those phrases and expressions could be stored into an interpreter's memory, and use them when the corresponding Chinese counterparts appear. They are regarded as they are understood world-wide.

At the press conference, the interpreter should sometimes pay attention to the speech style of the speaker to get closer to the original talk. Take Premier Wen Jiaobao's Press Conference as an example, Premier Wen Jiaobao's talk is filled with traditional Chinese culture and his deep concern for our nation. It would be the interpreter's duty to deliver them to some extent. Also, some of the talks may be hid with some deeper meaning but it would be better not to get revealed in public, foreignizing method is a better alternative at that moment.

Example 6. mo dao jin nian chun jiang jin, ming nian chun se bei huan ren

Foreignization strategy is preferable for cultural translation, which preserves the original flavor and truly achieves the goal of enriching the target-language culture and promoting the communication between different cultures. Premier Wen is well-educated in Chinese culture. His talk is often loaded with Chinese culture-specific words. "mo dao jin nian 
chun jiang jin, ming nian chun se bei huan ren" is actually improvised by Premier Wen at the press conference, which is adapted from "ji yu luo cheng feng ri dao, ming nian chun se bei huan ren" written by Du Shenyan, a famous Chinese poet in Tang Dynasty. The interpreter offered the literal meaning by interpreting it into "Do not regret that the spring is departing, come next year as it will be twice as enchanting." In this way, it remains the style of Premier Wen Jiaobao'sspeech. The deeper connotation of the sentence is to encourage everyone that the global economy is recovering and we should have confidence in it.

\section{CRITICS ON DOMESTICATING AND ForEIGNIZING INTERPRETATION STRATEGIES FOR THE PRESS CONFERENCE}

As we all know, interpreters attending the press conferences are all among the top talents. The interpretations made by them are of high quality. However, the comprehension of Hamlet varies from reader to reader. So does the interpretations of the press conference. Personally, I agree with most of the interpretations. But I would like to point out a few things I may doubt whether there is another way to put it better, and they are just my personal views.

Example 7. According to the interpreter: I can see that you have put your question in a quite mild way. I know that there have been media reports which say that China has got more arrogant and tough. And some have put forward the so-called theory of China's triumphalism. You have given me an opportunity to explain how China sees itself.

Original version: I know that there have been media reports which say that China has got more arrogant and tough. And some have put forward the so-called theory of China's triumphalism.

In this sentence, three paralleling phrases appear together: "zhong guo ao man lun", "zhong guo qiang ying lun", "zhong guo bi sheng lun". The interpreter adopted domesticating approach to interpret the first two into "China has got more arrogant and tough"; but adopted foreignizing approach to interpret the third into "theory of China's triumphalism".

No matter from the view of layout or the angle of consistency, I think all of the three phrases are supposed to be interpreted with foreignizing approach.

Improved version: Actually in current public opinion, some views like Haughty China, Tough China, Unshakable China have appeared occasionally.

The improved version could be trimmer and neater in form. Also, the original tone stressed by the premier with three separate phrases are delivered as well.

Example 8. "qing tian zai bu sui wu shu, que yue chong yuan hui you shi" is interpreted with both methods into "there's no way to heal the wound in my heart, but there's one day when the half moon becomes full again", which explains the literal meaning of the sentence. But I deem that it would be better further explained combining the background under which the premier cited the sentence.

Improved version: There's no way to heal the wound in my heart, but there's one day when the half moon becomes full again. The history of Taiwan's parting the mainland could not be changed, but Taiwan and the mainland will finally be reunited someday.

By adding the second part which applies the cited meaning into reality, the audience will be better understanding the premier's quotation in the context.

\section{CONCLUSIONS}

Based on the study of the English version of Premier Wen Jiaobao's speech in the press conference, the author's discoveries are that domesticating approach and foreignizing approach are complementary to each other. They can be adopted dividedly or together. When foreignization is adopted in translating paratactic phrases with Chinese characteristics, the author suggests paying attention to consistency in using the approach. When translating lines loaded with Chinese culture, the author suggests adopting both foreignization and domestication. With foreignization, the culture could be maintained to some extent, and with domestication, the meaning could be conveyed in a more clear way.

Generally, domesticating translation is smoother, simpler, clearer and more conventional. On the other hand, foreignizing translation is somewhat awkward, unnatural and unfamiliar and is full of exotic spirits. As for the premier's press conference, the purpose of the translation is to make the target-language audience to learn more about China's society, economy, politics, culture, and development, so that the language form should be familiar to the audience. Therefore, most examples in syntactical level and discourse level are adopting domesticating approach. But we can find out that most examples in lexical level and semantic level are adopting foreignizing approach in order to maintain the Chinese characteristics. Compared with domestication, foreignizing translation plays all important part in preserving the foreignness and otherness of the foreign culture.

With the increasingly prominent role China has played in the international society, the author suggests that foreignizing approach should be paid more attention to in the premier's press conference in order to promote Chinese culture. We not only need to be understood by adopting domesticating translation, but being spread out by using foreignizing translation is much more urgent at present. When it is difficult for the audience to comprehend, the author recommends that foreignizing translation plus explanation by domesticating method would be much better than mere domestication. Though it would cause complexity in expression and higher requirement for the audience, it would be 
rewarding from the perspectives of cultural communication, cultural integration, and the development of different languages in the long run.

\section{REFERENCES}

[1] Baker,Mona. (2004). Routledge Encyclopedia of Translation Studies. Shanghai: Shanghai Foreign Language Education Press.

[2] Bassent,Susan. (2004). Translation Studies. Shanghai: Shanghai Foreign Language. Education Press.

[3] Bell, Roger T. (2001). Translation and Translating. Theory and Practice. Beijing: Foreign Language Teaching and Research Press.

[4] Gentzler, Edwin. (1993). Contemporary Translation Theories. London\& New York: Routledge.

[5] Gideon, Toury,. (2001). Descriptive Translation Studies and Beyond. Shanghai: Shanghai Foreign Language Education Press.

[6] Munday, Jeremy. (2001). Introducing Translation Studies. U.K.: Routeldge.

[7] Newmark, Peter. (1981). Communicative and Semantic Translation: Approaches to Translation. New York: Pergamum Press.

[8] Newmark, Peter. (1988). Approaches to Translation. London: Prentice Hall.

[9] Newmark, Peter. (2001). Approaches to Translation. Shanghai: Shanghai Foreign Language Education Press.

[10] Nida, Eugene A. (1993) Language, Culture and Translating. Shanghai: Shanghai Foreign Language Education Press.

[11] Nida, Eugene A. (2004) Language and Culture: Contexts in Translating. Shanghai: Shanghai Foreign language Education press.

[12] Nida, Eugene A. (2004)Toward a Science of Translating, Shanghai: Shanghai Foreign Language Education Press, 2004.

[13] Nida, Eugene. A. (1982). Translating Meaning. California: English Language Institute.

[14] Nida, Eugene. A. (2004). Toward a Science of Translation. Shanghai: Shanghai Foreign Language Education Press.

[15] Nord, Christiane. (2001). Translating as a Purposeful Activity: Functionalist Approaches Explained. Shanghai: Shanghai Foreign Language Education Press.

[16] Pinkham, Jone. (2000). The Translator's Guide to Chinglish. Beijing: Foreign Language Teaching and Research Press.

[17] Reiss, Katharina. (1971). Possibilities and Limitations of Translational Criticism. Shanghai: Shanghai Foreign Language Education Press.

[18] Reiss, Katharina. (2000). Translation Criticism: Potential and Limitations. Manchester: St Jerome and American Bible Society.

[19] Shuttleworth,.(2004). Dictionary of Translation Studies. Shanghai: Shanghai Foreign Language Education Press.

[20] Venuti, L. (2004). The Translator's Invisibility. London and New York: Routledge.

[21] Vermeer, Hans, J (1978). Framework for a General Theory of Translating. Heidelberg: Heidelberg University.

[22] Vermeer, Hans, J. (1989). Skopos and Commission in Translational Activity. London: Routledge.

[23] Wilss, Wolfram. (2001). The Science of Translation: Problem arid Methods. Shanghai: Shanghai Foreign Language Education Press.

Xuedong Shi was born in Huhhot, Inner Mongolia, China in 1974. He received his MA degree in translation in Middlesex University, Britain, in 2004. He is currently a lecturer in the Foreign Language Department, Beijing Information Science University, Beijing, China. His academic research mainly focus 